\title{
“¿Es muy difícil! ¡Es muy difícil!” Quando as barreiras linguísticas conduzem à margem: a necessidade de um acolhimento intercultural e de uma formação pedagógica em línguas
}

\author{
“¡Es muy difícil! ¡Es muy dificil!” Cuando las barreras lingüísticas \\ conducen al margen: la necesidad de una acogida intercultural y de una \\ formación pedagógica en lenguas
}
“'Es muy dificil! ¡Es muy dificil!” When language barriers lead to the margin: a need of Intercultural Reception and a pedagogical training in languages

\author{
Dra. Simone Beatriz Cordeiro Ribeiro ${ }^{1}$ \\ Dr. Gilvan Müller de Oliveira²
}

\begin{abstract}
Resumo
As fronteiras são comumente marcadas pelo ir e vir de sujeitos em busca de atrativos, atendimentos, oportunidades e até mesmo moradia. Assim, as pessoas movidas por diferentes motivos transpõem fronteiras frequentemente e, uma vez perpetrado como algo cotidiano, as dificuldades de comunicação são ofuscadas quando está em jogo o emprego de línguas semelhantes, como é o caso da língua portuguesa e da língua espanhola que permeiam a Tríplice Fronteira Brasil, Paraguai e Argentina. Contudo, somente aqueles que precisam se comunicar através de outras línguas compreendem como a falta de conhecimento delas prejudica a interação, principalmente, quando se encontram fora do seu país de origem. Diante disso, objetiva-se refletir sobre a maneira como ocorre a recepção e alocação de estudantes estrangeiros nas instituições de ensino municipal de Foz do Iguaçu, no Ensino Fundamental I, cuja língua materna não é o português, e se há ou não a necessidade de uma educação em línguas com foco no ensino de segunda língua. Para tanto, foram realizadas entrevistas com professores que já tiveram ou têm alunos estrangeiros e com a equipe pedagógica das escolas, procurando refletir sobre as práticas pedagógicas empregadas ou que contribuiriam de maneira mais adequada quando em contato com crianças estrangeiras falantes de outras línguas. Desse modo, empregam-se pressupostos teóricos concernentes às Políticas Linguísticas (OLIVEIRA, 2013; VON BORSTEL, 2013, OLIVEIRA e SILVA, 2-17), Acolhimento Intercultural e Ensino de Línguas (RIBEIRO, 2018), e Ensino de Línguas para crianças (FERREIRA, 2013; FERREIRA e SANTOS, 2010).
\end{abstract}

Palavras-Chave: Acolhimento Intercultural, Barreiras Linguísticas, Políticas linguísticas, Segunda Língua, Tríplice Fronteira Brasil, Paraguai e Argentina.

\section{Resumen}

Las fronteras son comúnmente marcadas por el ir y venir de sujetos en busca de atractivos, atenciones, oportunidades e incluso vivienda. Así que las personas movidas por diferentes razones cruzan las fronteras a menudo y, una vez cometida como algo cotidiano, las dificultades de comunicación se ven opacadas cuando está involucrado el uso de un lenguaje similar, como el portugués y el español que permean la Triple Frontera Brasil, Paraguay y Argentina. Sin embargo, sólo aquellos que necesitan comunicarse a través de otras lenguas comprenden cómo la falta de conocimiento de ellas perjudica la interacción, principalmente, cuando se

\footnotetext{
${ }^{1}$ Pós-doutoranda em Linguística pela Universidade Federal de Santa Catarina (UFSC); Docente da Universidade Federal da Integração Latino-Americana - UNILA, Foz do Iguaçu, Paraná, Brasil; Ciclo Comum de Estudos; simone.ribeiro@unila.edu.br

${ }^{2}$ Professor Orientador da Universidade Federal de Santa Catarina - UFSC, Florianópolis, Brasil. Coordenador Geral da Cátedra UNESCO Políticas Linguísticas para o Multilinguismo; gimioliz@gmail.com
} 
encuentran fuera de su país de origen. Por lo tanto, el objetivo es reflexionar sobre la forma en que está la recepción y asignación de estudiantes extranjeros en las instituciones educativas municipales de Foz de Iguazú, en la escuela primaria, cuya lengua materna no es el portugués, y si hay o no la necesidad una educación en lenguas que se centra en la enseñanza de segunda. Para ello, se realizó entrevistas con profesores que ya tuvieron o tienen alumnos extranjeros y con el equipo pedagógico de las escuelas, buscando reflexionar sobre las prácticas pedagógicas empleadas o que contribuirían de manera más adecuada cuando en contacto con niños extranjeros hablantes de otras lenguas. En este sentido, se emplean teóricos concernientes a las Políticas Lingüísticas (OLIVEIRA, 2013, VON BORSTEL, 2013, OLIVEIRA y SILVA, 2-17), Acogida Intercultural y Enseñanza de Lenguas (RIBEIRO, 2018), y la enseñanza de lenguas para niños (FERREIRA, 2013, FERREIRA y SANTOS, 2010).

Palabras clave: Acogida Intercultural, Barreras lingüísticas, Políticas lingüísticas, Segunda Lengua, Tríplice Frontera Brasil, Paraguay y Argentina;

\begin{abstract}
Borders are commonly marked by the coming and going of subjects in search of attractions, services, opportunities and even housing. Therefore, people moved for different reasons, often cross borders and once perpetrated as something daily, the difficulties of communication are overshadowed when the use of a similar language is involved, such as Portuguese and Spanish language, that overstep the Triple Frontier Brazil, Paraguay and Argentina. However, only those who need to communicate through other languages understand how their lack of knowledge harms the interaction, especially when they are outside their home country. Therefore, the objective is to reflect on the reception and allocation of foreign students in the municipal education institutions of Foz do Iguaçu in the Elementary School, whose mother tongue is not Portuguese and whether or not there is a need of language education focused on second language teaching. To carry out it, interviews were conduct with teachers who already had or have foreign students and with the pedagogical team of the schools, trying to reflect on the pedagogical practices employed, or that would contribute in a more appropriate way, when in contact with foreign children speakers of other languages. Thus, theoretical assumptions concerning Linguistic Policies are used (OLIVEIRA, 2013; VON BORSTEL, 2013, OLIVEIRA e SILVA, 2-17), Intercultural Reception and language teaching (RIBEIRO, 2018), and Language teaching for children (FERREIRA, 2013, FERREIRA and SANTOS, 2010).
\end{abstract}

Keywords: Intercultural Reception, Language barriers, Linguistic Policies, Second language, Triple Frontier Brazil, Paraguay and Argentina.

\title{
1. Introdução
}

A cartografia dos territórios tem demonstrado que os limites e definições dos espaços físicos se estabelecem e se definem em diversos âmbitos, sejam políticos, históricos, ou geográficos. Diante disso, a fronteira, que sempre esteve marcada por conflitos e disputas de terras, serve como um demarcador territorial, sendo vista e considerada como o início e/ou o fim de uma região, onde inicia e termina uma nação, um estado, um município, um domínio político.

A fronteira ademais de um marcador físico, retrata e sugere identidades e, ao mesmo tempo em que define os sujeitos que nela transitam igualmente os diferencia. Isso ocorre porque no espaço fronteiriço se chocam culturas que em contato e em conflito se transformam e se reconstroem. Assim, ao transpor fronteiras os sujeitos levam e trazem consigo histórias de vida, modos de viver diferenciados e até mesmo línguas diferentes, pois "o movimento de pessoas traz consigo o movimento de línguas” (OLIVEIRA e SILVA, 2017, p. 133). 
Deste modo, em panoramas transfronteiriços, como é o caso da cidade de Foz do Iguaçu, Paraná, inserida na Tríplice Fronteira Brasil, Paraguai e Argentina, verifica-se que, em virtude de um considerável fluxo comercial, turístico e imigratório, a presença e o contato com estrangeiros são práticas cotidianas e corriqueiras. São situações as mais diversas e variadas que possibilitam e condicionam enunciados multilíngues, destacando a diversidade linguística que mosaica o viver neste cenário fronteiriço.

Portanto, a fronteira é marcada pelo constante ir e vir de sujeitos que passam a vivenciar outras experiências, culturas, costumes e, no caso de fronteiras internacionais, outros idiomas, como é o caso do Brasil que faz divisa, em sua maior parte, com países cuja Língua Oficial é a Língua Espanhola, a exceção de Guiana, Guiana Francesa e Suriname.

Embora as línguas portuguesa e espanhola tenham a sua origem na raiz latina, há costumes, culturas e usos linguísticos diversificados. Essa diversidade linguístico-cultural fronteiriça por si já sugere abordagens e planejamentos de cunho político linguístico voltados e focados na interculturalidade e no multilinguismo, com vistas a integração entre as nações, uma vez que "grande parte dos imigrantes que chegam ao país de acolhimento possui pouco ou nenhum domínio da(s) língua(s) oficiai(s)" (OLIVEIRA e SILVA, 2017, p. 135). Situação que dificulta a comunicação e impõe barreiras linguísticas que acabam por infringir direitos constituídos.

Diante disso, objetivando analisar a realidade educacional iguaçuense e como ocorre a recepção, a alocação e o ensino de português para estudantes imigrantes, foca-se o presente estudo nas instituições de ensino municipal, Ensino Fundamental I, procurando refletir sobre a necessidade ou não de um acolhimento intercultural e de uma formação docente em línguas que atenda a demanda desses alunos.

Para tanto, foram realizadas 19 entrevistas, em 11 escolas municipais iguaçuenses, com professores que já tiveram ou têm alunos imigrantes/estrangeiros e com representantes das equipes pedagógicas, procurando refletir sobre as práticas pedagógicas empregadas quando em contato com crianças imigrantes falantes, especialmente, de Espanhol Língua Materna.

Sob esta perspectiva de ensino de línguas valoriza-se um ensino e um aprendizado plurilíngue que considera tanto a abordagem sociolinguística de ensino e aprendizagem de Língua Materna, como também de Segunda Língua. Dessa forma, espera-se contribuir ainda para que os sujeitos envolvidos percebam e reflitam que, por meio de uma Educação em Línguas é possível propiciar "ganhos sociais para as pessoas e melhorar sua qualidade de vida" (MOITA LOPES, 2006, p. 41). 
Para tanto, na seção dois são discutidos alguns pressupostos do percurso metodológico, a construção do roteiro de entrevista semiestruturada e a definição dos participantes da pesquisa. Já a seção três foi elaborada de maneira que a fundamentação teórica dialogasse com às percepções dos Entrevistados sobre o acolhimento e alfabetização de crianças imigrantes. Para tanto, refletiu-se, primeiramente, a respeito da conversão da documentação escolar e da aplicação de avaliações diagnósticas, para na sequência discorrer sobre a metodologia de ensino da Língua Portuguesa vigente nas escolas municipais iguaçuenses.

\section{Metodologia}

Por se tratar de uma pesquisa de natureza aplicada realizou-se uma investigação in loco com o intuito de coletar dados a partir da observação, da elaboração e da aplicação de uma entrevista semiestruturada que foi gravada e transcrita. Por conseguinte, o estudo se ajusta em análises qualitativas e quantitativas que foram obtidas através de inter-relações com a cultura local e estrangeira, a partir da Língua Espanhola e da Língua Portuguesa, haja vista o contexto de contato linguístico propiciado pela Tríplice Fronteira Brasil, Paraguai e Argentina. Deste modo, definiu-se como campo de investigação a cidade de Foz do Iguaçu, localizada nessa região tri nacional, que conta com 51 instituições de ensino municipais, no que diz respeito ao Ensino Fundamental I.

Nesta primeira etapa da pesquisa foram realizadas 19 (dezenove) entrevistas com representantes das equipes pedagógicas e com os professores que têm ou já tiveram alunos estrangeiros, principalmente hispano falantes, de 11 escolas. $O$ roteiro de entrevista semiestruturado foi elaborado com base em 4 campos: A - Dados pessoais e socioculturais; B - Atitudes; C - Didático, pedagógico e curricular; D - Função (escala de bem, regular e mal), e conta com 66 questões. Logo, os parâmetros de seleção dos participantes foram estabelecidos com base em propostas futuras para o ensino de Português como Segunda Língua aos discentes imigrantes, que em 2017 contabilizavam mais de 350 matrículas distribuídas entre o $1^{\circ}$ e $5^{\circ}$ ano.

Os dados de amostragem foram analisados sob os paradigmas científicos da pesquisa quantitativa e qualitativa, partindo dos pressupostos estabelecidos por Flick (2004), Lüdke e André (1986) e Sandín Esteban (2010), com vistas a refletir sobre a realidade vivenciada pelas instituições de ensino municipal no que tange, principalmente, à presença de alunos hispano falantes e à metodologia de ensino de Língua Portuguesa. 
Dessa maneira, esta pesquisa de campo de aplicada suscita e sugere uma política linguística pensada e elaborada em conjunto com a participação de diversos segmentos da sociedade, haja vista que um estudo nesses moldes terá melhores condições de atender as emergências do próprio grupo a qual se destina. Ou seja, um planejamento bem engajado na esfera da comunidade permite "uma reação coletiva positiva frente às novas demandas da globalização e da inclusão cultural e linguística" (OLIVEIRA, 2013, p. 13)

\section{3. “Meu Deus, o que a gente fez com essa criança?”: o contexto de alfabetização de alunos falantes de Espanhol Língua Materna}

Em cenários fronteiriços como o iguaçuense evidencia-se, comumente, uma situação de imigração, em que os habitantes dessas regiões transitam entre um país e outro em busca de melhores condições de vida e oportunidades de trabalho e/ou estudo. Em alguns casos, deslocam-se sozinhos e, em outros, levam e trazem consigo a sua família ou parte dela. Nesta movimentação, adultos e crianças abandonam aquilo que conhecem e do qual fazem parte para adentrarem em um território novo, por vezes desconhecido, e, ao se aventurarem neste, se deparam com uma forma de vida totalmente diferenciada e, às vezes, com línguas e culturas diferentes.

Presentes, mas nem sempre inseridos na nova comunidade, esses imigrantes, principalmente hispano falantes, haja vista a cartografia da América do Sul e, em especial neste estudo, a Tríplice Fronteira Brasil, Paraguai e Argentina, passam a frequentar os diversos setores da nova sociedade, especialmente, educacionais. Nestes, crianças e adolescentes são matriculados e enquanto aguardam a documentação brasileira frequentam as aulas e são submetidos aos conteúdos e disciplinas presentes nos currículos de ensino brasileiros.

Assim sendo, ao pesquisar sobre a política linguística e educacional do município de Foz do Iguaçu, no que se refere às Línguas de Fronteira (português e espanhol), e o perfil dos professores do Ensino Fundamental I, assim como o perfil dos alunos e da extensão desses quanto à interlocução das Línguas de Fronteira neste município de fronteira geográfica enunciativa com Paraguai e a Argentina, procurou-se refletir sobre a importância de uma formação em línguas e de um acolhimento intercultural que atenda a demanda estudantil, pois 
é necessário para que possamos pensar sobre nossos atos e a respeitar as diferenças que existem e como a educação é um direito de todos, trabalhar de forma inclusiva e integradora com todos que ali estão é um caminho que deve ser seguido para que possamos remodelar conceitos e entendimento de sociedade. E discutir sobre assunto, mostrará de uma forma geral qual é o papel que o profissional professor que atua nessas áreas de fronteira, o que eles fazem para mediar o que o conhecimento ali com um aluno paraguaio que muitas vezes não entende o que ele fala quais as ações que esse professor toma para poder melhorar a vida daquele educando com o que ele quer transmitir. (LIMONGE et al. 2016, p. 30 - grifos nossos).

Segundo informações apresentadas por Ribeiro (2018), em 2017, haviam 372 alunos de nacionalidades estrangeiras matriculadas em 41 das 51escolas municipais iguaçuenses, sendo 315 paraguaias e 31 argentinas. Pode-se inferir a partir desses dados que, de um lado, tanto profissionais da educação quanto alunos brasileiros têm contato com falantes de espanhol e, de outro, que muitas crianças veem "para a escolarização no Brasil sem compreender a língua portuguesa, tornando o processo de alfabetização um entrave, pelo fato dos professores não conseguirem uma comunicação dialógica com estes alunos" (OLIVEIRA e RIBEIRO, 2016, p. 36), como exemplifica o Entrevistado 01 ao relatar o caso de uma criança paraguaia que chegou à sua sala chorando e, ao ser questionada, disse: “iEs muy difícil! ¡Es muy difícil!’”:

\footnotetext{
ENTREVISTAD0.01 - R: 01

Agora pra ela chegar e falar "es muy difícil”, ela deve ter ouvido muito português também... né, mas ela foi... foi uma experiência assim... nossa ... chocou... porque eu pensei assim, Meu Deus, o que a gente fez com essa criança né... ela viu o quadro cheio e pensou e agora? [...] E agora e uma criança né... ela já vem do país, onde tudo é diferente, chega já assustada, aí no primeiro dia de aula se depara com aquele texto e a professora muitas vezes diz assim: vamos [estalando os dedos], rápido... porque as crianças já estão no hábito de fazer rápido, da professora falar... agora ela pensa assim, a professora vai chegar aqui e vai mandar eu fazer rápido, o que que eu vou fazer se eu não estou entendendo nada do que tem ali... né... nossa eu fiquei chocada... A partir daquele dia toda criança que vem [de outro país] eu já falo pra professora: olha, ela está chegando hoje, um pouquinho de paciência... né, por causa dessa experiência, mas até então, toda a criança que chegava nós não tínhamos assim o cuidado de pensar que ela estava vindo de outro país e com outra língua. Era como se fosse assim: é uma obrigação da criança aprender o português... né. (Entrevista em 02/04/2018 - grifos nossos).
}

O relato do Participante 01 retrata o cotidiano vivenciado nas fronteiras marcado pelo constante ir e vir que, na maioria das vezes, diante da facilidade no fluxo imigratório, acaba ofuscando a realidade de quem transita e vivencia o habitar (n)a fronteira, como, por exemplo, o frequentar uma escola e as dificuldades de ser um estrangeiro e de não saber a língua da nova nação de moradia. No caso deste Entrevistado, que há 25 anos alfabetiza crianças, é possível perceber que após passar pela experiência descrita houve uma conscientização da 
realidade vivenciada pelos discentes imigrantes e, ao se colocar no lugar da aluna, permitiu-se compreender como a mesma se sentia.

Contudo, nem sempre essa é a realidade, Ribeiro (2015), em sua pesquisa de doutorado, deparou-se com situações em que as pessoas não compreendiam como as barreiras linguísticas condicionavam os estrangeiros e os imigrantes à marginalidade e como o simples fato de não dominar a língua portuguesa lhes suprimia oportunidades. Isso ocorria não apenas porque o imigrante não conhecia a língua portuguesa, mas principalmente porque o brasileiro fronteiriço com o Paraguai não conhecia a língua de seus vizinhos.

Situações como as descritas são muito comuns em regiões de fronteira que tratam do par linguístico português e espanhol, pois a similaridade entre essas duas línguas sustenta o estereótipo de línguas fáceis e que não precisam ser ensinadas ou aprendidas, no entanto, "somente os sujeitos que precisam se comunicar por meio desses idiomas compreendem como a falta do conhecimento de um deles prejudica a comunicação e os conduz à margem" (RIBEIRO, 2018, p. 950).

\section{1 "Na maioria das vezes é feita uma prova para ver em qual nível estão e colocar eles na turma": a conversão documental e a inserção de alunos imigrantes nas séries brasileiras}

Embora recebam instruções da Secretaria Municipal de Educação quanto à conversão de documentos de alunos imigrantes, cada escola tem autonomia para realizá-la de acordo com os casos que chegam até ela. Deste modo, a alocação desses imigrantes fica condicionada à perspectiva de inserção da instituição a ser frequentada que, geralmente, realiza avaliações diagnósticas para verificar em qual série a criança se encaixa:

\section{ENTREVISTADO.10 - R: 01}

Na maioria das vezes é feita uma prova para ver em qual nível estão e colocar eles na turma. (Entrevista em 02/04/2018).

\section{ENTREVISTAD0.07 - R: 01}

Quando [a criança] vem de fora ela entra na idade da série [correspondente] ou na série que a gente vê que é compatível e aí a gente vai fazendo avaliação para mudála de série. Não tem uma regulamentação para isso, a escola que faz. (Entrevista em $19 / 03 / 2018$ - grifos nossos).

\section{ENTREVISTAD0.01 - R: 02}

Olha, quando nós recebemos... a gente pela idade da criança e pelo que ela diz que estudava no Paraguai, nós colocamos numa turma... Se ela vem no terceiro ano nós 
colocamos no segundo, mesmo para ela ir se habituando à língua. Se a gente percebe que está acompanhando, aplica uma avaliação na criança e faz a classificação, mesmo porque... essas crianças vindas do Paraguai, elas vem tudo numa idade assim... bem além da série em que estão, chegam com doze anos no segundo, no terceiro, ai nós fazemos a classificação. (Entrevista em 02/04/2018 grifos nossos).

Assim, esse procedimento de avaliação diagnóstica é aplicado tanto quando não há uma documentação exata ou mesmo na ausência de uma, visando, deste modo, classificar o aluno em uma determinada série, como para as crianças que possuem documentação escolar do seu país de origem, seja como forma de verificação ou reclassificação:

\begin{abstract}
ENTREVISTAD0.06 - R: 01
É Feita uma avaliação para ver em que nível a criança está, a alfabetização, a matemática. Agora se a criança já trás a documentação e está tudo certinho aí a gente pode fazer só para dar uma confirmada. Nós que fazemos essa avaliação, a escola tem avaliações diagnosticas da Secretaria e nós também elaboramos de acordo com o planejamento da série. (Entrevista em 23/03/2018 - grifos nossos).
\end{abstract}

\begin{abstract}
ENTREVISTAD0.11 - R: 01
Eles vêm com a documentação do país de origem deles e passam por umas provas aqui no Brasil para tentar reclassificar e colocá-los na série adequada para eles poderem acompanhar. Então são avaliações que são feitas... vem da Secretaria de Educação uns modelos e aí eles vão ser adequados aqui, segundo, terceiro ou quarto ano que eles vão entrar. [...] Cada caso é um caso: eles vêm do país de origem para o quarto ano, já tem a documentação para o quarto ano, aí a gente faz uma reclassificação aqui para ver como consegue acompanhar o português, como que ele consegue e tal, mas ele já está inserido no quarto ano; outros a gente faz a reclassificação para saber em que série que ele vai entrar, Então depende, cada caso é diferente, né? São muito particulares... (Entrevista em 21/03/2018 - grifos nossos).
\end{abstract}

Como cada caso é considerado em suas particularidades, pode-se dizer que a avaliação diagnóstica serve, ainda, como parâmetro para "medir" o conhecimento linguístico que esses alunos possuem da Língua Portuguesa e, a partir do resultado, verificar se estão aptos ou não a acompanhar determinada série, assim como informaram os Entrevistados 07 e 11. Contudo, são práticas como essa que, na maioria das vezes, contribuem ainda mais para que o imigrante se sinta excluído e marginalizado, pois a língua e a cultura que sempre fizeram parte da sua vida não são consideradas na nação em que agora o mesmo se encontra.

A esse respeito, intensifica-se que as crianças "devem aprender a língua estrangeira [Segunda Língua] a partir do conhecimento que têm da sua língua materna e do

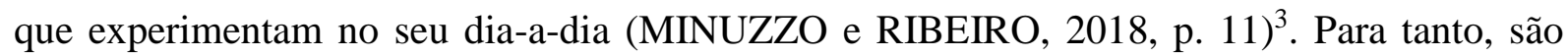

\footnotetext{
${ }^{3}$ Trecho original: "deben aprender la lengua extranjera a partir de los conocimientos que poseen de su lengua materna y a partir de lo vivenciado en su cotidiano" (MINUZZO e RIBEIRO, 2018, p. 11).
} 
necessárias reflexões nos cursos de formação de professores quanto à "importância da língua materna das crianças na alfabetização" (HORST, 2009, p. 82).

\subsection{O ensino de Português para falantes de Espanhol Língua Materna: "pois é... aí depende de cada professor"}

Ribeiro (2015), em sua tese de doutorado desenvolvida no município de Guaíra, Paraná, fronteira com Salto del Guairá, Paraguai, ao pesquisar sobre o ensino e a inserção da Língua Espanhola no Ensino Fundamental I constatou também que, embora houvessem discentes imigrantes vindos do Paraguai, não havia uma metodologia de ensino da Língua Portuguesa como Segunda Língua voltada ao acolhimento linguístico e intercultural desses alunos. Segundo a pesquisadora, havia um "despreparo da equipe pedagógica e docente em auxiliar e ensinar esses alunos que não dominam a Língua Portuguesa, uma vez que a sua Língua Materna é outra” (RIBEIRO, 2015, p. 209).

Deste modo, assim como Ribeiro (2015), outros pesquisadores também têm realizado pesquisas que envolvem a alfabetização de crianças falantes de espanhol em regiões fronteiriças, como, por exemplo, Marchesan e Ramos (2014) que tratam do ensino de português como língua estrangeira na fronteira Brasil-Uruguai; Josgrilbert e Boufleur (2012), Limonge et al. (2016) e Oliveira e Ribeiro (2016) que discutem a alfabetização de paraguaios na fronteira de Ponta Porã e Pedro Juan Caballero, assim como o papel do pedagogo frente a multiculturalidade em regiões de fronteira; e Ribeiro (2018) que discute a necessidade de um acolhimento intercultural e de um ensino de português como Língua Adicional para as crianças imigrantes das escolas municipais de Foz do Iguaçu, localizada na Tríplice Fronteira Brasil, Paraguai e Argentina.

A presença de pesquisas nesta área demonstra uma preocupação crescente que versa sobre a necessidade de um ensino de Português como Segunda Língua para imigrantes, principalmente, hispano falantes, em regiões de fronteira. Assim, como não há na prática uma metodologia de alfabetização específica para os discentes imigrantes, a aprendizagem fica, de certo modo, comprometida e dependente da iniciativa de cada docente que podem ou não se utilizarem de diferentes métodos "para garantir o ensino-aprendizagem de todos" (OLIVEIRA e RIBEIRO, 2016, p. 39). Como pode ser observado na fala do Entrevistado 05: 
lei que fale sobre essa... questão da língua... Tem para a inclusão de deficientes auditivos, essa coisa toda, mas assim, pra estrangeiro eu já não conheço... Se tem eu desconheço a lei. O que acontece também muitas vezes a gente não tem nem o professor especializado, teria que ter no município um professor especializado nisso daí, por exemplo, nós temos crianças que pega atestado... atestado de 30 dias. Aí nós temos um professor especializado só pra atender em casa essa criança, mas nesse caso específico... a gente não sabe. (Entrevista em 20/03/2018 - grifos nossos).

É evidente no enunciado do Participante 05 que não há uma formação específica para o trabalho pedagógico com crianças imigrantes ou estrangeiras, mas isso não justifica um ensino voltado para a maioria, uma vez que abordagens como essa não contribuem para a integração entre os discentes, colegas, professores e o ambiente escolar, pois reforçam a marginalidade e comprometem a aprendizagem:

\title{
ENTREVISTAD0.03 - R: 01
}

É a mesma metodologia. Você trabalha e o aluno vai ali, coitado, ele vai atrás aos barrancos, vamos dizer assim, né... Se você não... se a família em si também não ajudar... (Entrevista em 29/03/2018 - grifos nossos).

A esse respeito, Oliveira e Ribeiro (2016) esclarecem que

\begin{abstract}
é notável também a fragilidade de alguns professores no sentido de encarar esta realidade, em diálogo com professores alguns afirmaram que não sabem o que fazer pois não sentem-se preparados para receber estas crianças, os mesmos sentem-se de mãos atadas, pelo fato de não terem aprendido como lidar com esta realidade em seus cursos de formação profissional (OLIVEIRA e RIBEIRO, 2016, p. 36).
\end{abstract}

Como nem sempre há uma formação pedagógica que aborda o acolhimento intercultural e/ou um ensino de Português como Segunda Língua voltada aos discentes imigrantes, cuja Língua Materna não é a portuguesa, o processo de alfabetização fica comprometido, pois o docente não tem certeza em como deve proceder e à criança resta ouvir e tentar retirar algum significado das instruções e conteúdos enunciados na escola:

\section{ENTREVISTADO.07 - R: 02}

A gente não ensina o espanhol. A gente às vezes ouve uma criança [falando espanhol] e o que a gente tenta é falar bem devagar para que ela possa entender. $E$ o que a gente tenta fazer. (Entrevista em 02/04/2018 - grifos nossos).

Embora se discutam políticas interculturais ou inclusivas nos cursos de Pedagogia e Magistério, nem sempre as formações dão suporte aos docentes em suas práticas pedagógicas, visto que a "inclusão implica o respeito e a valorização das diferenças e da diversidade, a promoção da educação com vistas na garantia dos direitos humanos" (SANTANA, 2018, p. 
84). Assim, ademais de falar mais devagar para ser entendido é preciso ouvir e procurar entender o outro em sua língua ou na tentativa de uso da Segunda Língua, uma vez que

quando há uma interação reciproca, as duas culturas interagem de maneira horizontal e nenhuma delas se coloca acima da outra, pois esta relação implica que haja respeito na heterogeneidade e mesmo que nem sempre as relações vivenciadas na diversidade se deem sem conflitos, estes podem ser deliberados a partir do diálogo e do respeito, ou seja, através da prática da interculturalidade (RIBEIRO, 2017, p. 4).

Portanto, é preciso que a sua língua seja considerada e valorizada no processo de alfabetização, assim como "o contexto em que o aluno vive, sua cultura, sua história e sua identidade" (HORST, 2009, p. 81). Assim, estratégias que envolvem o respeito e a reciprocidade contribuem para uma melhor relação com a linguagem e com o meio em que se está inserido, porém:

\section{ENTREVISTADO.08 - R: 01}

Não, a gente fala em português. (Entrevista em 02/04/2018 - grifos nossos).

A relação que se tem na fronteira, tanto na interação cotidiana com falantes de outras línguas e nações, como no dia a dia da sala de aula, ainda se dá, por boa parte da comunidade brasileira, de maneira monolíngue, sendo vista por muitos com muita normalidade, como algo corriqueiro. Nesta perspectiva, o processo de aquisição da linguagem por imigrantes não precisa ser revisto, pois sempre existiu e sempre vai existir:

\section{ENTREVISTAD0.08 - R: 02}

Então assim os que são mais desenvoltos... desde o começo eles escrevem muito errado, misturam bastante, pra falar também, mas como são pequenos, é questão de dias, rapidinho eles se adaptam e eles conseguem, a criança consegue fazer bem essa troca: na escola só fala e escreve em português, em casa só fala em guarani ou em espanhol, e eles conseguem muito bem diferenciar essas duas. (Entrevista em 02/04/2018 - grifos nossos).

A partir do exposto pelo Participante 08, pode-se dizer que o processo da aquisição linguística é visto como temporário, como algo que vai se resolver rápido e de modo espontâneo, pois “rapidinho eles se adaptam” (ENTREVISTADO, 08, 2018). Porém, "rejeitar a língua materna de uma criança é rejeitar a própria criança, uma vez que a língua é a expressão de sua identidade e cultura" (HORST, 2009, p. 81). Abster-se e simplesmente aceitar a realidade monolíngue é concordar com o excludente. É aceitar que "os que são mais desenvoltos" (ENTREVISTADO, 08, 2018), representam um todo e não uma determinada 
parcela. É encarar o progresso lento e doloroso de aquisição da linguagem como falta de interesse e/ou preguiça de aprender, quando na verdade, dado o contexto enunciativo existente na fronteira, o “papel do pedagogo é valorizar a língua materna dos alunos 'paraguaios' que atravessam a linha de fronteira para serem alfabetizados no Brasil, tendo que se adequar a uma nova língua que é o português e ao método utilizado na alfabetização" (OLIVEIRA e RIBEIRO, 2016, p. 39).

Portanto, adaptar-se ao grupo não é uma tarefa fácil e precisa da atenção do docente. Diante disso, a metodologia não pode ser a mesma e voltada exclusivamente para a maioria, bem como dependente apenas das ações do professor, como pode ser verificado:

\section{ENTREVISTADO.13 - R: 01}

A metodologia é a mesma. A gente só da um suporte [coordenação], aula de apoio que é um reforço pela tarde. É por conta do professor. (Entrevista em 28/03/2018 grifos nossos).

\section{ENTREVISTADO.12 - R: 01}

Não é usada uma metodologia diferente. A gente tenta no máximo possível colocar a criança num reforço se ela tem muita dificuldade. (Entrevista em 23/03/2018 grifos nossos).

\section{ENTREVISTADO.06 - R: 02}

Oficialmente não [metodologia diferenciada]. O que acontece é uma orientação informal por parte da coordenação. Aqui na escola como eu tenho essa formação em espanhol, os professores me procuram para tentar auxiliar. (Entrevista em 23/03/2018 - grifos nossos).

Ante a situação exposta pelos Participantes está evidente que, geralmente, as crianças imigrantes são encaminhadas para o reforço. Neste, são atendidos pelo professor responsável pela sala de reforço ou sala de apoio. Apesar de serem salas com recursos diferenciados, no caso de alfabetização de imigrantes, não há garantias de que o docente possua formação específica para a prática pedagógica de ensino de Português como Segunda Língua. Consequentemente, o mesmo ocorre quando são encaminhados à coordenação, salvos alguns casos como o explicitado pelo Entrevistado 06, no recorte 02, em que a coordenadora tem formação em Língua Espanhola, possibilitando que surjam práticas diferenciadas advindas da sua formação em Letras.

Assim, sem formação adequada e, muitas vezes sem conhecimento da Língua Materna desses alunos imigrantes, principalmente paraguaios e argentinos, os professorem tentam, da maneira que lhes parece possível, amenizar o impacto linguístico: 


\section{ENTREVISTAD0.07 - R: 01}

Não. O que o professor tenta fazer é dar uma atenção especial para o aluno, porque o conteúdo a gente vai trabalhando. O que a gente tenta é de alguma forma amenizar o máximo possível, mas o conteúdo da turma é o conteúdo dele. (Entrevista em 02/04/2018 - grifos nossos).

\section{ENTREVISTADO.14 - R: 01}

É feito um trabalho diversificado. Tem sim a língua portuguesa, mas vai também pelo nível de compreensão de cada criança, se ela entende ou não. Quando a criança é estrangeira, a gente procura adaptar ela, mas geralmente é um conteúdo só. $E$ metodologia do professor. A gente vai modificando de acordo a necessidade do aluno. (Entrevista em 23/03/2018 - grifos nossos).

\section{ENTREVISTADO.04 - R: 01}

O ensino é para todos da mesma forma. Se eles vêm de fora [outro país] a política que a escola adota é de não corrigir os erros descontando pontos. No dia a dia a gente vai corrigindo, mas na hora de avaliar a gente não desconta por eles escrever errado ou se frase não tem um sentido óbvio. O importante é ele transmitir o conteúdo. (Entrevista em 19/03/2018 - grifos nossos).

Em consequência da falta de um apoio e de uma formação mais embasada, os docentes procuram dar uma atenção especial aos discentes imigrantes, seja ao falar mais pausado ou na não penalização de notas pelo emprego de transferências linguísticas da sua Língua Materna. No entanto, é "de extrema importância que se invista numa educação multicultural que, não somente busque conhecer as diferentes línguas e culturas, mas também integrá-las, respeitando assim a diversidade étnica cultural e linguística dos educandos" (HORST, 2009, p. 82), para que o atendimento considerado diferenciado não se restrinja aos descritos e à aplicação de exercícios extras e conteúdos iniciais de alfabetização e letramento de séries anteriores:

\section{ENTREVISTAD0.08 - R: 03 \\ Sim, tem que ter uma metodologia diferente. Eu por exemplo peguei uma apostila de primeiro ano, onde tem a letrinha "a" para fazer todo aquele trabalho, da letra "a", aí falar é "a", repete o "a", tem quatro tipos de "a" que você vai encontrar, "a" minúsculo, né... (Entrevista em 20/03/2018 - grifos nossos).}

Como nem todo docente tem domínio da Língua Materna de seus alunos imigrantes, a interação comunicativa dificilmente acontece. Deste modo, situações como as descritas podem surgir frequentemente. Assim sendo, a escola impõe barreiras à aquisição linguística dos alunos imigrantes que precisam se adaptar urgentemente ao português para cumprir com as exigências escolares, principalmente, por se posicionar contrária a esses falantes minoritários e por não possuir educadores "qualificados para trabalhar com esses grupos, pois dependendo da região, além de faltar uma qualificação na formação desses professores, na 
grande maioria das vezes o professor não possui conhecimento da língua materna e da cultura dos educandos" (HORST, 2009, p. 82).

Situações como as descritas pelos Participantes reforçam que é preciso refletir a respeito da importância e da necessidade de considerar a Língua Materna das crianças imigrantes e/ou estrangeiras no processo de alfabetização que envolvam Segundas Línguas. Os docentes "podem ajudar as crianças a continuarem usando as suas variedades linguísticas, na medida em que, por exemplo, pesquisem e incentivem o multilinguismo dos alunos em sala de aula, compartilhando as línguas através de exemplos práticos trazidos pelas crianças" (HORST, 2009, p. 81), preservando e garantindo a interação comunicativa em sua língua nativa, como propõe o Participante 03:

\section{ENTREVISTADO.03 - R: 02}

Olha, para o [nome do aluno] eu falo assim... "¿quieres que yo hable en portugués o en español?", eu pergunto para ele, por exemplo. Anteontem ele falou assim "ahh caiu mi pantalón”, a pecinha do quebra cabeça, aí eu perguntei "¿que quê é isso?". É calça. Daí eu falo para ele, "en portugués nosotros hablamos pantalones como calça". Calça? Sim. "Casco" ele falou outro dia, "olha ele está com casco", daí as crianças "ah?" Aí eu expliquei "[nome do aluno] este em português se chama capacete". Assim né?.... (Entrevista em 29/03/2018 - grifos nossos).

Ações como as relatadas pelo participante 03 devem ser fomentadas e compartilhadas, pois "nota-se o quão importante é a interação e o papel do professor alfabetizador nesta questão do multiculturalismo presente nas escolas da fronteira, para que a criança não perca a sua identidade cultural e sinta-se incluída no contexto escolar" (OLIVEIRA e RIBEIRO, 2016, p. 39).

A esse respeito, o Participante 10 enfatiza que o ensino de Português para imigrantes precisa de uma metodologia diferenciada e que os permita manterem-se bi ou plurilíngues:

\section{ENTREVISTADO.10 - R: 02}

O conteúdo é passado o mesmo, só que a gente sempre tem que ter atividade diferenciada e um método diferenciado para cada um, dependendo da sua dúvida. $E$, principalmente, os alunos que tem outra língua, a gente tem que ensinar a língua portuguesa de modo que não tire a língua tradicional deles. (Entrevista em 02/04/2018 - grifos nossos).

Sendo assim, preocupar-se com a manutenção da Língua Materna das crianças imigrantes é fundamental e requer medidas urgentes de conservação e prosseguimento de estudo, combatendo o apagamento linguístico. Ribeiro (2018), durante a execução de um projeto de ensino de português como Segunda Língua, ao observar três irmãos paraguaios de 
9, 8 e 7 anos, pôde constatar que a falta de uma metodologia com esse viés estava contribuindo para o apagamento de suas Línguas Maternas:

\begin{abstract}
o irmão de 9 anos fala em espanhol e em guarani, mas que prefere falar em português porque está no Brasil e todos falam em português; o irmão de 8 anos que está na $1^{\mathrm{a}}$ série fala pouca coisa em espanhol, palavras soltas, alternando com o português e fala guarani porque foi ensinado, mas acha muito chato. Segundo ele o português é muito legal e é "a nossa língua"; o irmão de 7 anos que está na $1^{a}$ série fala apenas o português e acha uma língua muito legal, que tem uma "voz legal", entende em espanhol, mas apenas contesta em português (RIBEIRO, 2018, p. 268269).
\end{abstract}

É possível inferir, a partir da citação, que a perda linguística das crianças se dá de maneira muito rápida e gradativa, isto é, a Língua Guaraní nem aparece no repertório do irmão de 7 anos e enquanto o irmão de 8 anos comunica-se muito pouco em espanhol, o de 9 fala muito bem e o de 7 só entende. Portanto, promover práticas que visem à manutenção da Língua Materna das crianças imigrantes, bem como o respeito e a possibilidade de uso de suas línguas em sala de aula é uma realidade emergente que precisa ser considerada e planejada.

\title{
4. "Era como se fosse assim: é uma obrigação da criança aprender o português": Algumas considerações
}

A sociedade contemporânea ao mover-se por posturas e anseios plurais, sugere e vivencia ações e experiências das mais variadas, cuja multiplicidade de sentidos propiciada na e pela globalização apresenta contextos super diversificados em que teorias estáticas e desconexas das relações sociais cotidianas não são mais suficientes. Assim, políticas linguísticas que fomentem a manutenção da Língua Materna dessas crianças e que promovam o ensino de Português como Segunda Língua são urgentes e essenciais para a promoção do plurilinguismo e para a garantia dos direitos linguísticos.

A crença de que o professor não precisa saber ou dominar a língua a ser ensinada ou a língua de seus discentes, traz inúmeros prejuízos e problemas de aquisição linguística e identitária aos alunos que, nesta perspectiva, são vistos como seres que nada sabem. Deste modo, um ensino defasado e com lacunas em seu planejamento e execução interfere no progresso do educando que pode passar a experimentar uma sensação de inferioridade, frustração e impotência. Portanto, a sala de aula deve apresentar-se como um ambiente em que as crianças possam experimentar e ter sucesso. Para tanto, a postura do professor deve ser a de mediador e incentivador, demonstrando empatia e respeito. Os chamados "erros" devem 
ser vistos como tentativas de acerto, pois sem tentativas e as "inadequações" não há um aprendizado reflexivo e que se (re)constrói na prática. Longe de uma obrigação e uma imposição, o ensino e a aprendizagem de línguas devem ser prazerosos, motivadores e criativos, uma vez que exigem tanto do discente quanto do docente, dedicação, planejamento, dinamismo, interação e paciência.

Deste modo, ademais de reconhecer a diversidade linguístico-cultural fronteiriça, é necessário planejar e propor políticas linguísticas de acolhimento linguístico e intercultural que visem à integração entre as nações e a diminuição das barreiras linguísticas que acabam por infringir direitos constituídos.

\section{Referências}

FLICK, Uwe. Uma introdução à pesquisa qualitativa. 2. ed. Porto Alegre: BOOKMAn, 2004.

HORST, Cristiane. A situação da alfabetização dos falantes de línguas de imigração no contexto brasileiro. In Revista Contingentia, v. 4, n. 2, nov. 2009, p. 73-84, 2009.2 Disponível em: seer.ufrgs.br/index.php/contingentia/article/download/11417/6762 Acesso em ago. 2018

JOSGRILBET, Maria de F. V; BOUFLEUR, Emne M. A ação docente na fronteira entre dois países frente à multiculturalidade: diversidade $\mathrm{e}$ diferenças culturais na perspectiva do processo civilizatório. In Anais XIV Simpósio Internacional Processos Civilizadores: 'Civilização, fronteiras e diversidade' e IV Seminário do Grupo de pesquisa 'Educação e Processo Civilizados', 2012, Dourados - MS, p. 1-13, 2012.

LIMONGE, Guilherme; et. al. Alfabetização de alunos paraguaios no âmbito escolar brasileiro. In Revista Magsul de Educação da Fronteira, v. 1, n. 1, dez. 2016, p.27 -33, 2016. Disponível em: bibmagsul.kinghost.net/revista2016/index.php/educfronteira/article/download/.../124 Acesso em ago. 2018

LÜDKE, Menga; ANDRÉ, Marli E. D. A. Pesquisa em educação: abordagens qualitativas. São Paulo: EPU, 1986.

MARCHESAN, Maria T. N; RAMOS, André G. Língua, fronteira e o ensino de português como língua estrangeira. In Revista Fórum Linguístico, v. 11, n. 2, abr.jun. 2014, p. 178-87, 2014.

MINUZZO, Cinthia I. G; RIBEIRO, Simone B. C. La enseñanza de la Lengua Española y de la Lengua Portuguesa bajo la perspectiva de Lenguas de Frontera en la red de enseñanza municipal de Foz do Iguaçu, Paraná. In Anais do XIII Seminário nacional de Literatura, História e Memória. 2017. Cascavel. UNIOESTE. 2018, p. 1-18. Disponível em http://www.seminariolhm.com.br/2018/simposios/19/simp19art04 .pdf Acesso em jan. de 2018. 
MOITA LOPES, Luiz P. da. Uma linguística aplicada mestiça e ideológica: interrogando o campo como lingüista aplicado. In MOITA LOPES, Luiz P. da. (Org.). Por uma linguística aplicada INdisciplinar. São Paulo: Parábola, 2006, p. 13-42.

OLIVEIRA, Gilvan M. de. Políticas linguísticas como políticas públicas. 2013. Disponível em: http://e-ipol.org/wp-content/uploads/2013/06/Politicas_linguisticas_e_Politicas_publicas. pdf. Acesso em setembro de 2013.

; SILVA, Julia I. da. Quando barreiras linguísticas geram violação de direitos humanos: que políticas linguísticas o Estado brasileiro tem adotado para garantir o acesso dos imigrantes a serviços públicos básicos? In Revista Gragoatá. v. 22; n. 42, jan.-abr. 2017, p. 131-153. Disponível em: http://www.gragoata.uff.br/index.php/gragoata/article/view/909 Acesso em março de 2018.

OLIVEIRA, Jaqueline D. de O; RIBEIRO, Silvana V. Desafios encontrados pelos professores no processo de alfabetização de alunos paraguaios em escolas brasileiras da região de fronteira. In Revista Magsul de Educação da Fronteira, v. 1, n. 1, Dez. 2016, p.34-40, 2016. Disponível em: http://bibmagsul.kinghost.net/revista2016/index.php/educfronteira/article/view/140/125 Acesso em ago. 2018

RIBEIRO, Simone B. C. Língua(s) de fronteira: o ensino da língua espanhola em Guaíra, Paraná. 2015. 259 f. Tese de Doutorado (Doutorado em Letras). Universidade Estadual do Oeste do Paraná (Unioeste), Cascavel, 2015.

A Marginalidade em Detrimento da Interculturalidade em Regiões de Fronteira Geográfica Enunciativa. In RELACult. v. 3. Edição Especial, dez. de 2017, $\operatorname{artigo~}^{\circ}$ 510, p. 1 23, 2017.

Acolhimento Intercultural e Ensino de Português como Língua Adicional nas Escolas Municipais de Foz do Iguaçu. In Revista Domínios de Linguagem. v. 12; n. 1, março de 2018, p. 940-973, 2018.

SANDÍN ESTEBAN, Maria Paz. Pesquisa qualitativa: fundamentos e tradições. Trad. Miguel Cabrera. São Paulo: Artmed, 2010.

SANTANA, Maria L. da S. Práticas pedagógicas na região de fronteira: uma olhar a partir de escolas de Ponta Porã. In Revista Educação, v. 43, n. 1, jan./mar. 2018, p. 1-14, 2018. Disponível em: https://periodicos.ufsm.br/reveducacao/article/view/23299/pdf Acesso em ago. 2018. 